\title{
Communities of Practice as a tool to support the GCIO function
}

\author{
Luís Paulo Santos \\ Universidade do Minho \& INESC-TEC \\ Braga \\ Portugal \\ psantos@di.uminho.pt
}

\author{
Luís Nuno Barbosa \\ Universidade do Minho \\ Braga \\ Portugal \\ luisnuno.soares.barbosa@gmail.com
}

\author{
Diogo Aires Bessa \\ Universidade do Minho \\ Braga \\ Portugal \\ dagab8@gmail.com
}

\author{
Lúcia Pereira Martins \\ Universidade do Minho \\ Braga \\ Portugal \\ pereiramartins.lu@gmail.com
}

\author{
Luís Soares Barbosa \\ United Nations University (UNU-EGOV) \& INESC-TEC \\ Guimarães \\ Portugal \\ barbosa@unu.edu
}

\begin{abstract}
${ }^{\mathbf{1}}$
A Community of Practice ( $\mathrm{CoP}$ ) allows practitioners of a clearly defined domain to share knowledge, experience, and best practices. It provides a social context for practitioners, often distributed across multiple organizations, and emerged over the last few decades as a fundamental mechanism for knowledge sharing, management, and generation within organizations. Best practices, innovations, and solutions to shared problems first emerge within CoPs. These are, and must be perceived as, an investment in organizations' future and competitiveness.
\end{abstract}

Establishing a CoP is a straightforward process, the most challenging factor being the recruitment of members to attain critical mass. The challenge is to maintain the CoP active, with members contributing with high quality, innovative content. Increasing a CoP's medium / long-term survival probabilities requires careful planning to avoid incurring in some well-known pitfalls.

This paper proposes and discusses a set of nine guidelines for establishing and maintaining a community of practice within the context of Electronic Governance (EGOV) and Government Chief Information Officers (GCIO). This research was motivated by the initiative of the government of a developing country. Results are based on a review of the relevant literature, together with the detailed analysis of interviews to members or coordinators of large communities of practice. This analysis was further validated against the opinions of public servants directly involved on EGOV-GCIO-related functions during two focus groups meetings.

\footnotetext{
${ }^{1}$ Permission to make digital or hard copies of all or part of this work for personal or classroom use is granted without fee provided that copies are not made or distributed for profit or commercial advantage and that copies bear this notice and the full citation on the first page. Copyrights for components of this work owned by others than ACM must be honored. Abstracting with credit is permitted. To copy otherwise, or republish, to post on servers or to redistribute to lists, requires prior specific permission and/or a fee. Request permissions from Permissions@acm.org.
}

\section{CCS CONCEPTS}

- Applied computing E-government

\section{KEYWORDS}

Communities of practice, guidelines, Government Chief Information Officers

\section{ACM Reference format:}

L. Santos, L. Barbosa, D. Bessa, L. Martins, L. Soares Barbosa. 2018. Communities of Practice as a tool to support the GCIO function. In Proceedings of the $11^{\text {th }}$ International Conference on Theory and Practice of Electronic Governance, Galway, Ireland, April 2018 (ICEGOV'18), 9 pages. DOI: 10.1145/3209415.3209507

\section{INTRODUCTION}

A Community of Practice $(\mathrm{CoP})$ is a special type of community, in the sense that it is constituted by a group of people who, besides sharing a concern within a given domain, actively develop their daily activity - hence their practice - within this same domain. The CoP's members engage in joint discussions and share experiences, knowledge, and difficulties, and, together, develop a common practice to address these challenges [1]. CoPs greatly empower practitioners of a given domain, increasing their effectiveness and productivity, by allowing members to access, create and share collective knowledge, and strengthening professional identity, relationships and collaborations [2]. Simultaneously, CoPs are a major advantage to the organizations'

ICEGOV'18, April 4-6, 2018, Galway, Ireland (c) 2018 Association for Computing Machinery. ACM ISBN 978-1-4503-5421-9/18/04..\$15.00 https://doi.org/10.1145/3209415.3209507 
future and competitiveness; since best practices, innovations, and solutions to shared problems often emerge within CoPs.

The context for the work reported in this paper is provided by a governmental project on a developing country, whose goal is to advance the implementation and sustainability of the Government Chief Information Officer (GCIO) function, particularly through the establishment of the appropriate education and community structures. This paper proposes a set of nine guidelines for establishing and sustaining a community of practice (CoP) among public servants, within the context of Electronic Governance (EGOV) and Government Chief Information Officers. The aim is to foster EGOV-GCIO-related knowledge and experience sharing among public service practitioners, thereby facilitating the emergence and widespread acceptance of best practices within this domain. Public service institutions are extremely segmented into different agencies and departments, with knowledge and practice often contained within these organizational boundaries; CoPs can play a fundamental role by fostering people engagement and exchange of ideas across such boundaries, promoting a much more effective public service [3].

The proposed guidelines aim to facilitate keeping the CoP active and successful in the medium / long-term, avoiding incurring in the most common pitfalls associated with the failure of these communities. Additionally, these guidelines are explicitly associated with CoPs' lifecycle typical phases, allowing for the identification of each phase's key aspects.

Methodology - The research reported in this paper follows a four-stage methodology, including i) Literature Review, ii) Experts Interviews, iii) Focus Groups and iv) Synthesis, as depicted in Figure 1.

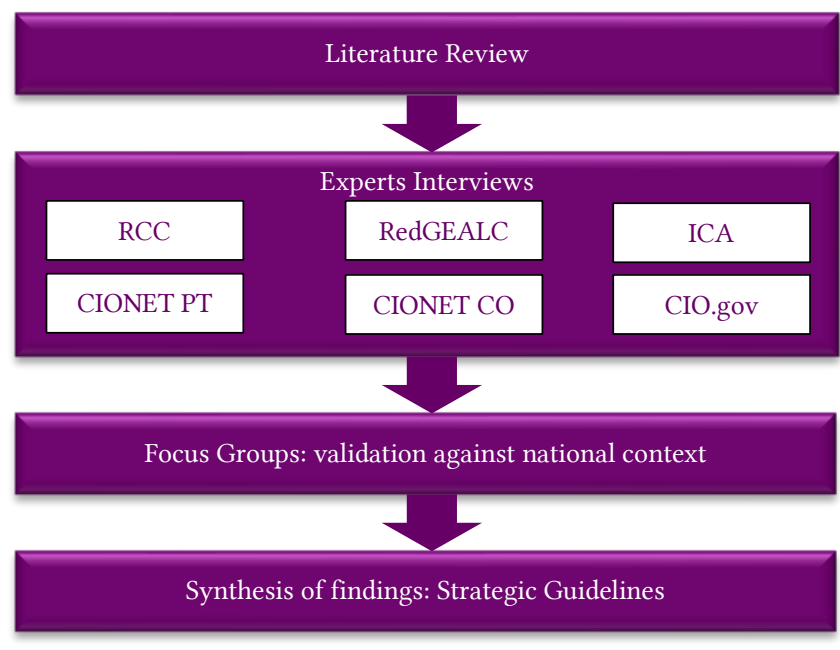

Figure 1 - Methodology: Research Activities

The Literature Review identified and documented the most significant research literature on CoPs, with a particular focus on those related to the public sector, performing a conceptual analysis, together with a thorough analysis of papers reporting the findings of empirical studies.
Expert interviews were conducted on six communities of practice from around the world. Whereas for all CoPs the respective coordinator was interviewed, for two of them a regular member of the community was also interviewed, thereby providing a complementary perspective. Interviews were analyzed along five dimensions of inquiry: context, activities, shared practice, motivations, and challenges.

Two focus group meetings gathered nine EGOV practitioners from different levels of government and different locations. These meetings sought to gain insight into the local e-government context, with respect to the establishment of an EGOV-CoP as perceived by the participants, besides validating, and further identifying, relevant issues in this process. A thorough analysis was performed, organized along six dimensions: context, motivation, activity model, success factors, operational model and membership, and IT support model.

The Synthesis of Findings activity produced a set of principles and guidelines for the establishment of an EGOV and GCIO-related $\mathrm{CoP}$, based on all the insights gained through the previous stages.

\section{LITERATURE REVIEW}

This section systematizes the main findings of the literature review process, organized along five dimensions of analysis: conceptual background, lifecycle, activity model, success factors, and risk factors.

\subsection{Conceptual Background}

In recent years, the role of communities in the process of learning and knowledge generation has attracted much attention from across the social sciences, interested in the acquisition, management, exchange, and dissemination of knowledge. This interest has influenced management literature and practice at an unexpected pace, mostly due to the consultancy role of some of the pioneers of research on CoPs [1] [4]. Wenger [1] provides a clear description of a CoP: "Communities of practice are a specific kind of community. They are focused on a domain of knowledge and over time accumulate expertise in this domain. They develop their shared practice by interacting around problems, solutions, and insights, and building a common store of knowledge".

By definition, communities are an aggregation of people (and/or organizations) that are bound to accomplish tasks or engage in sense-making activities [5] [6]. This approach focuses on informal and situated social interaction, rather than on a planned mechanistic process of cognitive transmission. Such interaction achieves authentic, motivated learning of what knowledge is required regarding the complexities of real practice. Active involvement in the practice is identified as a key process in learning. Fundamentally, learning becomes a social phenomenon and is placed in the context of a lived experience and participation in the world. CoPs are formed by groups of people in organizations that interact to share what they know, learning from each other, and to provide social context for their work. A CoP defines itself along three dimensions [6]: the Domain - a community of practice is not a mere network between people. It has a shared domain of interest, membership implying a 
commitment to the domain, and a shared competence that distinguishes members from other people; the Community members establish a relationship that enables them to learn from each other; the Practice - CoPs are formed by practitioners who develop and share resources, including experiences, stories, tools, and ways of addressing problems within the domain.

CoPs strengthen relationships between individuals, exhibiting characteristics such as: rapid flow of information and propagation of innovation, absence of introductory preambles, knowing what others know, what their capabilities are, and how participants can contribute to the enterprise or network, and shared ways of doing things together.

CoPs often exist independently of benefiting from institutional support; however, informed management usually encourages them in order to gain a competitive advantage [7].

\subsection{Lifecycle}

Communities are known to follow a lifecycle organized into four phases: Pre-Community / Chaos, Emergence, Vision, and Actualization [8]. Communities evolve by progressing through these phases, although not necessarily following a linear path. In particular, this is a cyclic behavior, meaning that well-developed communities might, and certainly will, return to the Chaos stage. Each of these phases is further decomposed into several stages, but the important lesson is that different phases require different actions in order to evolve towards more mature and resilient stages.

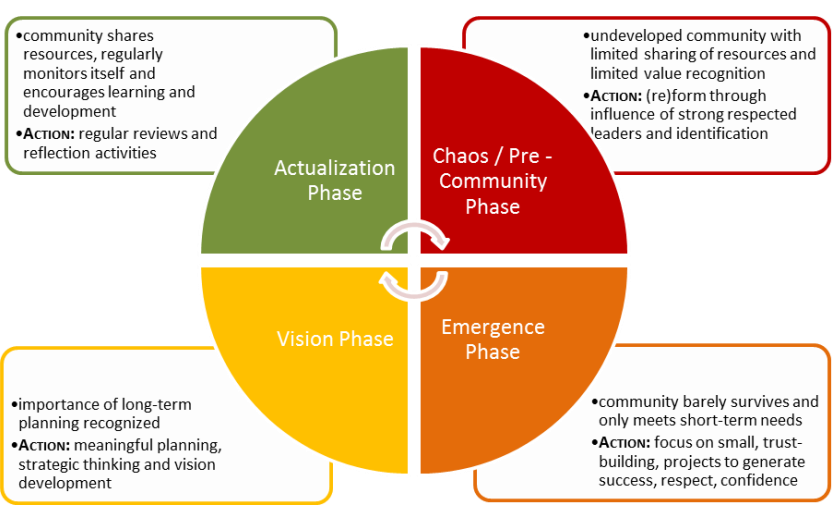

Figure 2 - Community Life Cycle (adapted from [8])

CoPs start with the process of asking for help (PreCommunity) main actions include building identity and finding a strong leadership. Groups of people with similar issues start to come together (Emergence) and build trust, respect, and confidence. A $\mathrm{CoP}$ is then formed (Vision), with a clear mission statement, meaningful planning, and strategic thinking, actualizing its own activities through systematic evaluation (Actualization). Finally, the community focus loses relevance and it may either disperse of evolve towards other domains (Chaos). Note, however, that knowledge should not cease to exist, thus CoPs, which are basically containers of knowledge, cannot actually die. Instead, the relevance of a $\mathrm{CoP}$ or of its core topic could face a decline, but its knowledge repository is still maintained [8] [9].

\subsection{Activity Model}

The activity model characterizes which activities will be promoted and supported within the scope of a CoP. Activity planning should never happen before the community goals have been clearly identified, and should actively involve all stakeholders, including community leaders, sponsors, and members. Common activity planning pitfalls [10] include: i) allowing for a wide range of activities rather than concentrating on giving robust support to a reduced set of prioritized activities, and ii) letting technology dominate decisions by failing to understand that a successful CoP is much more than the technology that supports its activities. Table 1 lists a set of activities and technological features associated with CoPs [10] [11]; a community must be initiated with a small set of such activities; as the community matures its members will call for the activities that make more sense.

Table 1 - Activities and technological features for CoPs

Category Functionalities / Activities

Social networking, discussion forums,

Member blogs, workshops and conferences, study

Interaction groups, explorative missions, member commenting, training, webinars

\begin{tabular}{ll}
\hline & Levels of achievements' badges (eventually \\
Member & $\begin{array}{l}\text { involving some gamification), rewards (e.g., } \\
\text { Recognition }\end{array}$ \\
& $\begin{array}{l}\text { conference or event free registration), } \\
\text { reputation management systems }\end{array}$ \\
\hline \multirow{3}{*}{ Content } & $\begin{array}{l}\text { File repositories, wikis, media albums and } \\
\text { libraries, data visualization tools, } \\
\text { collaborative document authoring tools, } \\
\text { public and password protected content }\end{array}$ \\
\hline Member & User-generated rating of contents, polls and \\
Feedback & surveys \\
\hline \multirow{3}{*}{ Social Media } & $\begin{array}{l}\text { LinkedIn), topic-specific or content-type- } \\
\text { specific (e.g., YouTube, Flickr, Scribd) social } \\
\text { media sites }\end{array}$ \\
\hline Project & $\begin{array}{l}\text { Project and task management tools, } \\
\text { decision support tools, calendars }\end{array}$ \\
\hline Utilities & $\begin{array}{l}\text { Notifications, centralized authentication, } \\
\text { metrics tools, API }\end{array}$ \\
\hline
\end{tabular}

\subsection{Success Factors}

CoPs are complex social structures very sensitive to subtle endogenous and exogenous dynamics, exhibiting a large number of factors that strongly influence its success or failure. Lave et al. [6] identifies a set of success factors and organizes them into three classes: personal, interpersonal (community), and organizational. Table 2 associates each success factor with the phase of the community lifecycle where it is most relevant or where special attention must be paid to that particular success factor. 


\subsection{Risk Factors}

Risk factors essentially consist of the absence of the above identified success factors. The most relevant risk factors include: lack of motivation and/or identification of the members with the $\mathrm{CoP}$, resistance to collaborate, mainly due to lack of trust, and lack of funding, time, and other resources.

Wenger et al. [1] notes that CoPs can become an obstacle to learning and innovation by keeping other practitioners hostages of the CoP's expertise and knowledge. Risk factors exogenous to the community are eventual legal constraints that might prevent the CoP from pursuing some goals or not allow it to adopt certain activities.

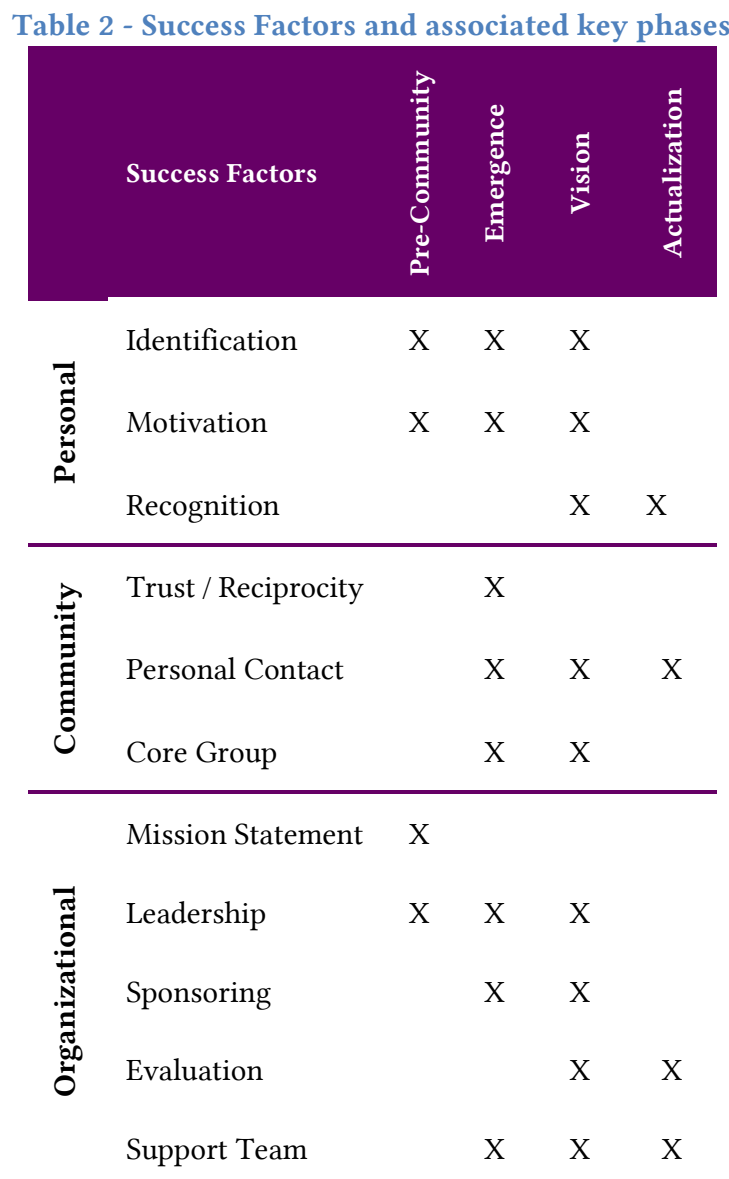

\section{EXPERT INTERVIEWS}

Expert interviews were used on this research work as a means of inquiry to provide this study with orientation and thematic structure, gathered from the interviewees' knowledge, expertise, and experiences. Eight expert interviews were conducted, addressing the following six communities of practice from around the world: i) CIO.gov - United States Federal CIO Council; ii) CIONET PT - CIONET Portugal; iii) CIONET CO - CIONET Colombia; iv) ICA - International Council for IT in Government Administration; v) RCC - Rede Comum do Conhecimento; vi)
RedGEALC - Red de Gobierno Electronico de America Latina e Caribe.

Whereas for all CoPs the respective coordinator was interviewed, for RCC and ICA a regular member of the community was also interviewed, thereby providing a complementary perspective. Each interview covers the following five dimensions of inquiry: 1. CONTEXT - what were the major factors leading to the creation of this community of practitioners?

2. ACTIVITIES - what activities, discussion, and sharing does the community promote between members?

3. SHARED PRACTICE - how does the community build its own memory, that is, is the interaction within the community recorded and accessible in some way?

4. MOTIVATIONS - why do individuals decide to join the community and what are the efforts undertaken by the community to engage new members?

5. CHALLENGES - what were the major challenges faced while implementing the community?

\subsection{Context}

All interviewees, especially the coordinators who were more familiarized with the reasons why the respective $\mathrm{CoP}$ was created, agree that the context for the creation of these communities settles on sharing experiences, practices, and knowledge. On a more concrete note, it is also mentioned by all that the $\mathrm{CoP}$ facilitates the standardization of procedures and allows for the development of a network of contacts. This last issue was particularly emphasized by the CIONET CO coordinator, remembering that the $\mathrm{CIO}$ positions can be very solitaire and the community allows members to develop a sort of common intelligence.

\subsection{Activities}

Activities promoted by all these CoPs can be broadly classified as either online, digital activities, or activities entailing personal, face-to-face contact.

The former include the CoP's portal, repository of information on a diversity of formats (written documents, audio, videos, webinars, programs and applications, etc.), newsletters, collaborative platforms, discussion forums, and blogs.

The latter, face-to-face activities, were most valued by the members of the CoPs and include members gathering at different geographic locations and thematic levels on conferences, workshops, seminars and study groups, thematic courses and mentoring programs, technical visits and exploratory missions. It was often referred as an added value the fact that these more 'formal' contacts, often lead to direct 'informal' contacts by phone and email to deal with quotidian challenges and difficulties that have already been faced by some of the CoP's members. Additionally, ICA members produce sectorial annual reports which are then summarized on a global report. This is highly valued by ICA members as a reference for current practices among members within the GCIO arena. 


\subsection{Shared Practice}

The interviewees agree that networking and sharing of experiences are the most valued shared assets of the respective communities. This is most often technologically supported, such as in the case of a knowledge repository where all tangible information can be stored and made available. Networking, knowing who is who and what is each member's expertise, as well as having access to these people, constitutes a less tangible sort of information and privileges, which is also highly valued.

With respect to the knowledge repository, interviewees claim to value study and working groups' reports - describing and justifying best practices - as well as the possibility to archive and exchange software developed by the community to handle particular public administration requirements.

\subsection{Motivations}

Knowledge sharing and pursuit is the principal motivation identified by all interviewees. Interactions among members, both online and personally, build a sense of identification and belonging, which adds up to motivation. Additionally, as claimed by CIO.gov's coordinator, the motivation is knowing that there is maybe a solution out there for our specific challenge, which another agency (member/institution in a more general sense) has already tackled. CIONET CO's coordinator remembers that it is not only the know-how that is relevant, but the know-who is highly motivating. This CoP nurtures personal contacts by organizing events on informal environments, so that CIOs can establish durable relationships.

It is stated that both endogenous and exogenous recognition acts as a powerful motivator. RCC's member stresses that belonging to the CoP improved the services delivered to citizens and this is well-prized among members. RCC's coordinator adds that the international prizes awarded to the CoP keep everybody motivated.

\subsection{Challenges}

Interviewees noted that, while it is not difficult to start a community, the challenge is to keep it active, motivated, and attracting new members. Outreach the community to get new membership is identified as a hard problem; this is especially relevant during the CoP's establishment phase, where potential members have to be approached with an intangible proposal.

For communities crossing international boundaries, it was noted that countries that are technologically more advanced can feel unmotivated to cooperate with underdeveloped ones, and some of them even create language barriers.

A very relevant challenge within the public administration realm are political cycles and political instability. Besides the challenge of maintaining the $\mathrm{CoP}$ active and motivated across these cycles, there is the issue of its political legitimacy. In some cases, the CoP's members maintained it until the new administration recognized the CoP's value for the organization.

Members of CoPs, rather than coordinators, stressed that people's resistance to change takes time to overcome and thus to fully exploit the CoP's benefits. The relevance of the support team is also mentioned. One of the communities recognized having been initially carried out by technology issues and not addressing the CIOs' real needs, namely, strategy guidelines.

\subsection{Experts' Interviews: Main Findings}

Table 3 summarizes the main findings drawn from the experts' interviews.

Table 3 - Experts' interviews: main findings

\begin{tabular}{|c|c|}
\hline Dimension & Summary \\
\hline \multirow{3}{*}{ Context } & $\begin{array}{l}\text { Sharing experiences, practices } \\
\text { knowledge }\end{array}$ \\
\hline & Standardizing procedures \\
\hline & Develop a network of contacts \\
\hline
\end{tabular}

Online: portal, knowledge repository, newsletters, collaborative platforms, discussion forums, blogs

Activities Personal contacts: conferences, seminars and study groups, thematic courses and mentoring programs, exploratory missions.

Annual reports

\begin{tabular}{cl}
\hline $\begin{array}{c}\text { Shared } \\
\text { Practice }\end{array}$ & $\begin{array}{l}\text { Knowledge repository } \\
\text { Networking }\end{array}$ \\
\hline \multirow{3}{*}{ Motivation } & Knowledge sharing and pursuit \\
& Recognition \\
& Networking \\
\hline & Recruiting members \\
& Political cycles and personnel turnover \\
Challenges & Identifying the most appropriate focus \\
& Gathering resources (e.g., \\
& administrative and technological \\
& support team)
\end{tabular}

\section{FOCUS GROUPS}

Two focus groups (FG) were conducted in order to gain insight into the participants' perception of the national context concerning the creation of an EGOV-CoP. The discussion in these FG was structured along six dimensions: context, motivation, activity model, success factors, operational model and membership, and IT support model.

\subsection{Context}

The aim was to understand what experience the participants had in communities of practice or similar organizations. Confusion between communities of practice and work teams repeatedly occurred, which calls for the need of a clear, consensual definition of a community of practice.

\subsection{Motivation}


This section of the meetings addressed the motivations that might be on the root of individuals' decision to actively engage in the discussion and activities of the community. It was our aim to understand what are, according to the participants' perception, the most important motivating factors for engaging in such a community.

Networking was one of the factors most referred to - the growing significance of the know-who, rather than the knowhow, was mentioned as a justification for its importance.

The opportunity to learn from peers was also seen as an important factor, as well as the consequent opportunity of standardizing practices among similar institutions. Participants agreed that it would add to the motivation any influence that the discussion and concerns of this community of practice could have on general policy-making.

Recognition by peers is a very important motivator, with some suggesting quantitative or qualitative ranking of the members within the community, according to the level of their commitment and enrollment in the activities of the community. How and by whom should participants be ranked was not consensual; possibilities discussed included an assessment by peers, based on the utility, correctness and/or impact of one's interaction and an assessment by a supervising entity.

\subsection{Activity Model}

We sought to understand which activities the participants regard as most important to increase the perceived added value of being a member of the CoP; these included:

- Discussions on online forums for practice sharing, which are very important to rapidly solve day-to-day situations;

- Conferences and workshops, eventually involving international experts, to keep up with the best international practices, and to foster personal contacts among members;

- Study groups and/or collaborative problem solving;

- Exploratory missions, which could consist of visiting and learning from similar institutions, or even from the private sector; - Activity reports at different levels, which would be documents gathering information of identified good practices that could be used as case studies;

- Training;

- Knowledge repository, where all information resulting from the above activities can be stored and easily accessed.

Activities that promote personal contact were highly valued among FG participants.

\subsection{Success Factors}

Unlike the opinions gathered in the expert interviews, keeping a passionate core group/leadership, eventually nominating a respected practitioner to nurture and coordinate the community, was not highly valued by the FG participants. The possibility of these (core group/leader) emerging naturally during the establishment of the community was, however, considered as probable and desirable.

Whereas a clear definition of the domain, mission statement and overall goals of the community was seen as very important, several participants warned that setting a very normative action plan would not be viable, and could even be prejudicial for the development of the community.

The evaluation of the community was discussed. The measurement of its effectiveness, considering dynamics and achievements, as well as the impact on organizational improvement and best practice development, was seen as very difficult to achieve.

\subsection{Operational Model and Membership}

Financial sustainability was the main topic addressed. It was generically unanimous that the practitioners should not finance the community themselves. Solutions pointed out were direct funding by the Government, fees paid by the institutions they belong to (which was argued to be quite difficult), and the self-sustainability of the community, which could be achieved by selling private institutions the access to some of its data, producing paid-for publications, finding funding sponsors, accepting paid memberships from the private sector, etc.

\subsection{IT Support Model}

Participants agreed on the importance of keeping a portal, including online discussion forums, a knowledge repository, support for more focused sub-communities and/or study groups, tools for e-learning, collaborative work and collaborative problem-solving environments, such as document editing, programming or project management tools, and tutorials for new public servants to be able to catch up with their jobs easily and faster.

According to the participants, this portal should integrate personal profiles, similar to those of social networks, and the members' ranking system. Newsletters would be welcome.

\subsection{Focus Groups: Main Findings}

Table 4 summarizes the main findings drawn from the experts' interviews.

Table 4 - Focus groups: main findings

\begin{tabular}{|c|c|}
\hline Dimension & Summary \\
\hline Context & $\begin{array}{l}\text { No experience among participants calls } \\
\text { for a clear, consensual definition of a CoF }\end{array}$ \\
\hline \multirow{4}{*}{ Motivation } & Networking \\
\hline & Recognition \\
\hline & Standardizing practices \\
\hline & Influence on policy-making \\
\hline \multirow{5}{*}{$\begin{array}{l}\text { Activity } \\
\text { Model }\end{array}$} & Online discussion forums \\
\hline & $\begin{array}{l}\text { Conferences, study groups, and } \\
\text { exploratory missions }\end{array}$ \\
\hline & Training \\
\hline & Activity reports \\
\hline & Personal contacts highly valued \\
\hline
\end{tabular}




\begin{tabular}{|c|c|}
\hline Dimension & Summary \\
\hline \multirow{4}{*}{$\begin{array}{l}\text { Success } \\
\text { Factors }\end{array}$} & Leadership not highly valued \\
\hline & $\begin{array}{l}\text { Clear, but not normative, mission } \\
\text { statement }\end{array}$ \\
\hline & $\begin{array}{l}\text { Evaluation perceived as hard to } \\
\text { achieve }\end{array}$ \\
\hline & $\begin{array}{l}\text { External evaluation balanced with } \\
\text { qualitative internal evaluation by } \\
\text { CoP's members }\end{array}$ \\
\hline \multirow{3}{*}{$\begin{array}{c}\text { Operational } \\
\text { Model }\end{array}$} & $\begin{array}{l}\text { Funding by the CoP's members seen } \\
\text { as highly undesirable }\end{array}$ \\
\hline & $\begin{array}{l}\text { Funding by the Government or public } \\
\text { agencies }\end{array}$ \\
\hline & $\begin{array}{l}\text { Self-sustainability by selling services } \\
\text { and products }\end{array}$ \\
\hline \multirow[t]{2}{*}{$\begin{array}{l}\text { IT Support } \\
\text { Model }\end{array}$} & $\begin{array}{l}\text { Single access portal integrating a } \\
\text { well-defined range of services and } \\
\text { tools; }\end{array}$ \\
\hline & Personal profiles and ranking system \\
\hline
\end{tabular}

\section{SYNTHESIS OF FINDINGS: GUIDELINES}

Building on the research conducted and documented in the previous sections, nine guidelines are proposed for the establishment of a sustainable community of practice, joining together Electronic Government practitioners and Government Chief Information Officers.

Table 5 summarizes the proposed guidelines and associates with the relevant communities' lifecycle phases, allowing for the identification of each phase key aspects.

Table 5 - Guidelines for a CoP

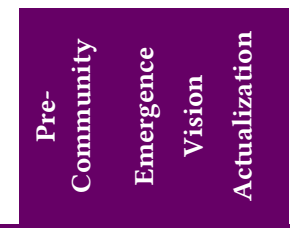
\#1 Definition of a clear mission statement
$\mathbf{X}$
\#2 Identification of opportunities and
$\mathbf{X}$ channels for participation: activities and services Foster motivation Establish the leadership structure Establish participation rules that foster trustworthy relationships
Establish the sponsoring structure and role
Clearly define membership requirements

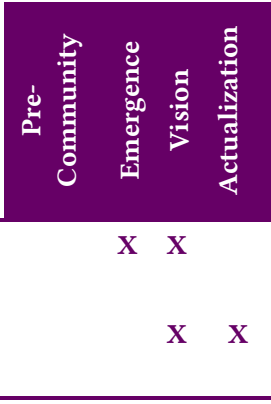

\subsection{Definition of a clear mission statement}

Members of a successful community of practice share a common identity. This is characterized by the domain in which they are interested, the practice - understood as the set of the members' unique perspectives, experiences, problem solving methodologies, needs, and concerns - and the community itself, in the sense that activities and shared knowledge continuously shape the community collective identity. Besides this common identity, a CoP must have a clear purpose, focus, and set of goals. Current and future members must understand why belonging to the $\mathrm{CoP}$ represents an added value, what they can expect from it, and what the community expects from them. This must be clearly stated on the CoP's mission statement. Definition of the mission statement must engage a broad set of stakeholders, in order to make it consensual, accepted by all peers and foster a sense of identity with the community itself.

\subsection{Identification of opportunities and channels for participation: activities and services}

The mission statement establishes the community's purpose and goals, but these have to be translated into actions, activities and services, which enable the respective realization. Participation in the community should be enabled by making available a balanced set of options and communication channels. It is important that there are multiple alternatives for members to communicate and share their knowledge, expertise, and experiences. However, community designers must be aware that providing too many options can disperse activity among many different channels and compromise its cohesion.

Participation channels must allow for different levels of participation, according to the members' digital literacy, expectations and interest.

Personal contact among members must be promoted. It was clear during literature review, experts' interviews, and focus groups that personal contact is highly valued and contributes to further motivation and identification with the CoP.

\subsection{Foster motivation}

Voluntary, pro-active participation of members on the CoP's activities will only happen if members are highly motivated. Motivation cannot be overestimated; motivated, pro-active members are key for the CoP's success and survival, even through intensive personnel turnover and political cycles. 
Strong motivators include knowledge sharing and learning, networking, and recognition by peers. Researchers and CoP's practitioners have recognized that gamification creates intrinsic motivation and increases member participation in CoP's activities [12]. Gamification can be defined as the transference of game thinking and mechanics to non-game contexts, with the aim of engaging users in problem solving. There are a few mechanisms that can be implemented on a CoP to bind recognition with gamification, such as [12]:

- Use points to reward given actions, providing a clear feedback on the progress of the member on the CoP;

- Use badges to reward concrete achievements;

- Use leaderboards to display the members relative rankings in terms of points and badges - leaderboards represent the social aspect of a system and reinforce the sense of relatedness.

\subsection{Establish the leadership structure}

Leadership is recognized as acritical factor for CoP's success. An adequate leadership structure guides, supports and renews the community overtime. It is essential to grant the $\mathrm{CoP}$ the required sponsorship and legitimacy and to face challenges like silo mentalities, lack of mandates or support, personnel turnover, and political cycles.

Forms of leadership can vary greatly from very salient, visible and daily moderation of community interactions to backstage support, coordination with sponsors, securing resources and political backing. Guidelines for establishing the leadership structure include:

- Select a community leader who is well connected, has competence and credibility within the field and the community, is passionate about the CoP's domain, has good communication skills and experience as a leader;

- Recognize and compensate the time required to lead the community;

- Identify community members with potential to become leaders, provide them with training and opportunities to assume leading roles within the $\mathrm{CoP}$.

\subsection{Establish participation rules that foster trustworthy relationships}

The degree of formalism of participation rules varies a lot among CoPs, going from tacit assumptions to clearly defined protocols guiding all interactions. The major driver of CoPs is knowledge sharing; members' willingness to engage on these activities strongly depends on their trust on the community and on the individual members. Guidelines for the design of such participation rules include:

- Involve core community members on modelling the desired behavior and on the elaboration of the participation rules;

- Explicitly enforce trustworthy behavior;

- Take into consideration any existing legal issues;

- Establish these rules from the beginning and post them on the community website, so that all members have easy access to them.

\subsection{Establish the sponsoring structure and role}

A proper sponsors' board is fundamental to the CoP's success from the emergence phase through the rest of its lifecycle. Strategic, well-connected sponsors can facilitate agreements among institutions, help secure financial resources and overcome legal constraints. In a governmental context and for CoPs crossing public agencies boundaries, sponsors are instrumental in providing CoP's leaders with guidance and providing the $\mathrm{CoP}$ with the organizational legitimacy it requires to meet its goals and to be accepted by the multiple actors, often embedded in very diverse contexts and reluctant to accept changes on how issues are handled and knowledge is used and protected.

\subsection{Clearly define membership requirements}

Interested practitioners must be clearly informed of what are the requirements to be accepted as a member of the CoP. Some communities are particularly restrictive, only allowing membership by invitation, for example. This level of privacy might allow for increased trust among members and deeper forms of knowledge sharing, but it obviously limits participation. Completely open communities may attract a large number of members, but trustworthy relationships and knowledge sharing can be harder to achieve and sustain.

\subsection{Establish mechanisms to secure financial sustainability}

CoPs are mostly informal networks, seldom endowed with a budget. However, CoP's activities can require substantial resources. Supporting the leadership structure and the support team, events' organization, portal design and implementation, IT infrastructure, CoP's promotion and awareness raising activities all require funding. Therefore, mechanisms to secure the CoP's financial sustainability have to be found. CoP's leaders must identify the most appropriate funding mechanisms, knowledgeable that financial requirements will increase with the community size. Main options include:

- Obtain funding from the management institution through a formal budget;

- Have the CoP's participants pay a membership fee - this raises an obstacle to participation, which can prevent the CoP from attaining the required critical number of members. An alternative is to have the public agencies they work for paying an institutional fee;

- Find sponsors who financially support the CoP;

- Have the CoP's activities generating profit to support the community through registration fees at conferences, nonmembers - especially from the private sector - paying access to the CoP's knowledge repository, charging for consultancy, among others.

\subsection{Evaluate the community health and effectiveness}

The effectiveness of a community is usually defined as the extent to which it meets its goals and provides value to its members and respective organizations. Evaluation becomes increasingly important as the $\mathrm{CoP}$ matures, with the actualization phase driven by evaluation feedback. Progressively more complex factors can 
be evaluated by resorting to more advanced evaluation techniques, starting from measuring activity level based on simple site analytics, to assessing impact and added value based on online surveys and focus groups.

Evaluation allows leaders to [13]:

- Determine what parts of the CoP are performing well and which are not, according to the community goals;

- Understand what are and how to meet the needs of different types of participants;

- Steer the CoP's activities towards greater effectiveness according to the evaluation results;

- Periodically report to the community;

- Demonstrate the impact of the community on attitudes, on practice, and on organizations' performance;

- Perform benchmarking, by comparing the $\mathrm{CoP}$ to others targeting similar audiences;

- Demonstrate the CoP's value near (potential) funders and sponsors.

\section{ACKNOWLEDGMENTS}

This paper is a result of the project SmartEGOV: Harnessing EGOV for Smart Governance (Foundations, Methods, Tools) NORTE-01-0145-FEDER-000037, supported by Norte Portugal Regional Operational Programme (NORTE 2020), under the PORTUGAL 2020 Partnership Agreement, through the European Regional Development Fund (EFDR).

\section{REFERENCES}

[1] E. Wenger, R. McDermott e W. Snyder, Cultivating Communities of Practice: A Guide to Managing Knowledge, Harvard Business Press, 2002.

[2] S. E. Booth, "Cultivating Knowledge Sharing and Trust in Online Communities for Educators,” fournal of Educational Computing Research, vol. 47, pp. 1-31, 2012.

[3] D. Garson, Public Information Technology and E-governance: Managing the Virtual State, Jones \& Bartlett Learning, 2006

[4] L. C. Li, J. M. Grimshaw, C. Nielsen, M. Judd, P. C. Coyte, I. D. Graham, "Use of communities of practice in business and health care sectors: a systematic review. Implementation Science, 4(1), 27, 2009.

[5] G. Ranmuthugala, J. Plumb, F. Cunningham, A. Georgiou, J. Westbrook e J. Braithwaite, "Communities of Practice in the Health Sector: A systematic review of the literature," Sydney, 2010.

[6] E. W. Jean Lave, Situated Learning: Legitimate Peripheral Participation, Cambridge University Press, 1991.

[7] F. Nickols, "Characteristics of A Community of Practice (CoP)," 2012. [Online]. Available: http://www.nickols.us/CoPCharacteristics.htm. [Acedido em 2016].

[8] Centre for Innovative \& Entrepreneurial Leadership, "Communities Life Cycle Matrix,” 2014. [Online]. Available: http://theciel.com/wpcontent/uploads/2014/08/Communities-Matrix-CIEL-v-2.2-.pdf. [Acedido em 2016].

[9] P. Gongla e C. R. Rizzuto, "Evolving communities of practice: IBM Global Services experience,” IBM Systems fournal, vol. 40, pp. 842-862, 2001.

[10 Project: Connected Online Communities, "Online Communities for Educators:

] Guidelines for Planning and Implementation,” 2011.

[11 Project: Connected Online Communities, "Technology for Online

] Communities of Practice," 2011.

[12 A. A. Carvalho, "To Enliven Virtual Communities of Practice through

] Gamification," EAI Endorsed Transactions on Serious Games, vol. 15, 2015.
[13 Connected Educators, "Resources and Tools for Evaluation of Online

] Communities of Practice," 2011. [Online]. Available: http://connectededucators.org/wp-content/uploads/2011/07/707_COCPEvaluation-Brief-July_2011.pdf. [Acedido em 2016]. 